Article

\title{
A New Algorithm for Delineation of Surface Depressions and Channels
}

\author{
Ning Wang $(\mathbb{D}$ and Xuefeng Chu *(1) \\ Department of Civil and Environmental Engineering (Dept 2470), North Dakota State University, P.O. Box 6050, \\ Fargo, ND 58108-6050, USA; ning.wang@ndsu.edu \\ * Correspondence: xuefeng.chu@ndsu.edu; Tel.: +1-701-231-9758
}

Received: 3 November 2019; Accepted: 15 December 2019; Published: 18 December 2019

\begin{abstract}
Topographic delineation is critical to watershed hydrologic modeling, which may significantly influence the accuracy of model simulations. In most traditional delineation methods, however, surface depressions are fully filled and hence, watershed-scale hydrologic modeling is based on depression-less topography. In reality, dynamic filling and spilling of depressions affect hydrologic connectivity and surface runoff processes, especially in depression-dominated areas. Thus, accounting for the internal hydrologic connectivity within a watershed is crucial to such hydrologic simulations. The objective of this study was to improve watershed delineation to further reveal such complex hydrologic connectivity. To achieve this objective, a new algorithm, HUD-DC, was developed for delineation of hydrologic units (HUs) associated with depressions and channels. Unlike the traditional delineation methods, HUD-DC considers both filled and unfilled conditions to identify depressions and their overflow thresholds, as well as all channels. Furthermore, HUs, which include puddle-based units and channel-based units, were identified based on depressions and channels and the detailed connectivity between the HUs was determined. A watershed in North Dakota was selected for testing HUD-DC, and Arc Hydro was also utilized to compare with HUD-DC in depression-oriented delineation. The results highlight the significance of depressions and the complexity of hydrologic connectivity. In addition, HUD-DC was utilized to evaluate the variations in topographic characteristics under different filling conditions, which provided helpful guidance for the identification of filling thresholds to effectively remove artifacts in digital elevation models.
\end{abstract}

Keywords: topographic delineation; depressions; channels; hydrologic connectivity; watershed modeling

\section{Introduction}

Surface depressions are one of the dominant topographic characteristics for many landscapes. For example, the Prairie Pothole Region (PPR) in North America is unique due to its numerous depressions. It can be a challenge to model hydrologic processes in such depression-dominated areas [1,2]. As a pre-processing procedure of hydrologic modeling, surface delineation is essential and critical to reveal hydrologic connectivity across a land surface. Many methods have been developed for surface delineation based on digital elevation models (DEMs) (e.g., [3-7]). In traditional delineation methods, however, depressions in a watershed (including artifact depressions) are commonly removed by implementing filling and/or breaching approaches [3,8-14]. That is, it is assumed in these methods that the entire watershed contributes surface runoff to its associated outlet. This assumption can be appropriate for watersheds with fewer depressions, but not for depression-dominated areas like PPR. In reality, depressions have threshold controls on the hydrologic connectivity of a watershed [15-17], and only a portion of the watershed contributes surface runoff to the outlet in most rainfall-runoff events. In recent years, various studies, which focused on investigating hydrologic connectivity and the related impacts on hydrologic processes, highlighted the significance of depressions [18-20]. Therefore, 
new watershed delineation methodologies are needed to capture the detailed connectivity between depressions and reveal the real hydrologic processes.

Generally, a typical depression consists of a ponding area and at least one threshold (i.e., pour point). Depressions in an area exhibit a hierarchical characteristic. Following a filling process, the depressions that share the same threshold can merge into a larger, higher-level depression $[15,16]$. Such a merging process continues until all highest-level depressions are generated. In the existing delineation methods, some algorithms focus on delineation of highest-level depressions only, while others center on characterizing all level depressions. For example, Temme et al. [21] developed an algorithm to search DEM cells for identification of the highest-level depressions and the algorithm was further incorporated into a geomorphological model, LAPSUS (landscape process modelling at multi-dimensions and scales), to investigate the dynamic landscape evolution. Arc Hydro is an ArcGIS-based tool that handles data pre-processing for hydrologic modeling [22]. Differently from the method by Temme et al. [21], in Arc Hydro all highest-level depressions are identified based on the differences between the fully filled DEM and the original DEM. Consequently, it cannot provide hydrologic connectivity between depressions. In addition, both methods do not consider channels in their surface delineation. Chu et al. [23] developed a puddle delineation (PD) algorithm to identify depressions at all different levels, and their associated thresholds and puddle-based units (PBUs). The PD algorithm was further used to provide depression information for hydrologic modeling to analyze the influence of depressions on hydrologic processes across various spatial scales $[15,17,24]$. Tahmasebi Nasab et al. [25] improved the PD algorithm by considering channels and developed a depression-dominated delineation (D-cubed) algorithm. In addition to depressions at different levels, the D-cubed algorithm further identifies PBUs and channel-based units (CBUs) based on the highest-level depressions and channels. The PD and D-cubed algorithms are mainly used for delineation of smaller scale surfaces.

The objective of this study was to reveal the internal hydrologic connectivity within watersheds. To achieve this objective, a new algorithm, HUD-DC, was developed for delineation of hydrologic units (HUs) associated with depressions and channels at a watershed scale. The performance of HUD-DC was evaluated by comparing it with Arc Hydro in an application to the Upper Pipestem Creek watershed in North Dakota. In addition, the original DEM was pre-filled with a series of incremental water depths to analyze the variations in topographic characteristics under different filling conditions and determine the filling threshold, which can be used to control or eliminate artifacts in DEMs.

\section{Materials and Methods}

\subsection{Development of HUD-DC}

HUD-DC implements ArcGIS-based surface delineation to reveal the hydrologic connectivity at a watershed scale by identifying a series of HUs, including PBUs and CBUs, and provides topographic information related to depressions and channels for hydrologic modeling in depression-dominated watersheds. Following Chu et al. [23] and Tahmasebi Nasab et al. [25], a PBU consists of a highest-level depression and its contributing area, while a CBU includes a channel segment and its contributing area. Moreover, one highest-level depression may have a number of embedded lower-level depressions. Since a PBU does not contribute water to its downstream HU(s) (PBU or CBU) until the highest-level depression of the PBU is fully filled and the focus of HUD-DC is on the surface delineation at a watershed scale, the dynamic merging and splitting of lower-level depressions within a PBU are not taken into account in HUD-DC. Compared with Arc Hydro, HUD-DC considers both depressions and channels when identifying contributing areas and provides the detailed connectivity between HUs. Similarly to the D-cubed algorithm, HUD-DC delineates a surface into numerous HUs (PBUs and CBUs) and determines their relationships and connectivity. However, instead of searching for depressions at all levels, HUD-DC only identifies the highest-level depressions, and new approaches are used in HUD-DC for watershed-scale surface delineation. To illustrate the methodology of HUD-DC, 
an artificial surface with $10 \times 10$ DEM grids (Figure 1a) was used in this study. Figure $1 \mathrm{~b}, \mathrm{c}$, respectively, show the fully filled DEM and the flow directions under a fully filled condition, both of which are utilized as input data of HUD-DC. The fully filled DEM was created by using the ArcGIS filling function, while the flow directions were determined by using the methods developed by Tarboton et al. [26] and Jenson and Domingue [5]. HUD-DC consists of two major modules, depression identification module and channel and HU identification module. Their procedures are detailed in the following sections.

\begin{tabular}{|c|c|c|c|c|c|c|c|c|c|c|}
\hline & 1 & 2 & 3 & 4 & 5 & 6 & 7 & 8 & 9 & 10 \\
\hline $\mathrm{A}$ & 50 & 49 & 50 & 47 & 47 & 47 & 47 & 47 & 47 & 50 \\
\hline $\mathrm{B}$ & 50 & 48 & 50 & 17 & 18 & 20 & 13 & 11 & 13 & 47 \\
\hline $\mathrm{C}$ & 50 & 47 & 16 & 46 & 46 & 46 & 12 & 10 & 12 & 47 \\
\hline $\mathrm{D}$ & 50 & 4 & 2 & 50 & 47 & 50 & 13 & 11 & 13 & 50 \\
\hline $\mathrm{E}$ & 50 & 3 & 1 & 48 & 50 & 49 & 48 & 47 & 20 & 48 \\
\hline $\mathrm{F}$ & 50 & 4 & 2 & 49 & 50 & 50 & 50 & 17 & 47 & 48 \\
\hline $\mathrm{G}$ & 50 & 5 & 3 & 50 & 46 & 45 & 50 & 16 & 50 & 50 \\
\hline $\mathrm{H}$ & 50 & 47 & 14 & 45 & 12 & 11 & 3 & 4 & 50 & 49 \\
\hline $\mathrm{I}$ & 50 & 50 & 48 & 13 & 48 & 48 & 50 & 10 & 48 & 49 \\
\hline $\mathrm{J}$ & 50 & 49 & 49 & 49 & 49 & 50 & 10 & 9 & 8 & 4 \\
\hline
\end{tabular}

(a)

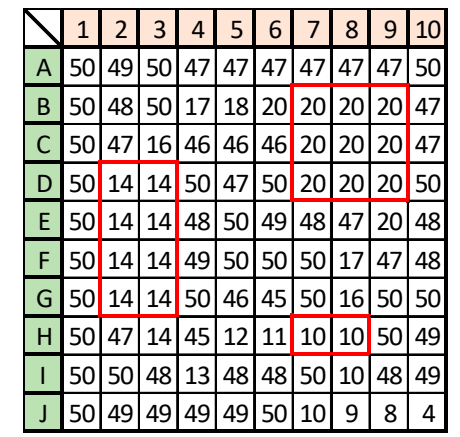

(b)

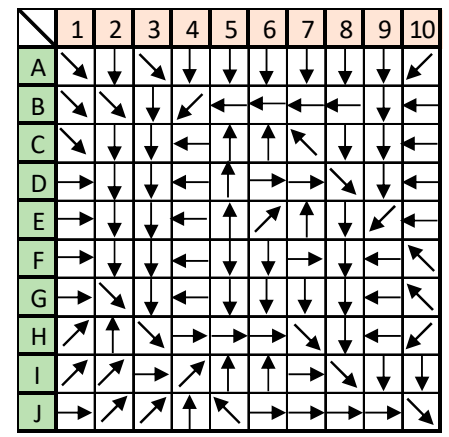

(c)

Figure 1. Input data of HUD-DC: (a) original DEM; (b) fully filled DEM; and (c) flow directions under the fully filled condition.

\subsubsection{Identification of Depressions}

Figure 2 shows the flowchart of the depression identification module. The identification of depressions includes four major steps: (1) identification of the filled cells; (2) searching for possible depression cells; (3) elimination of 'fault' depression cells; and (4) identification of 'real' depression cells.

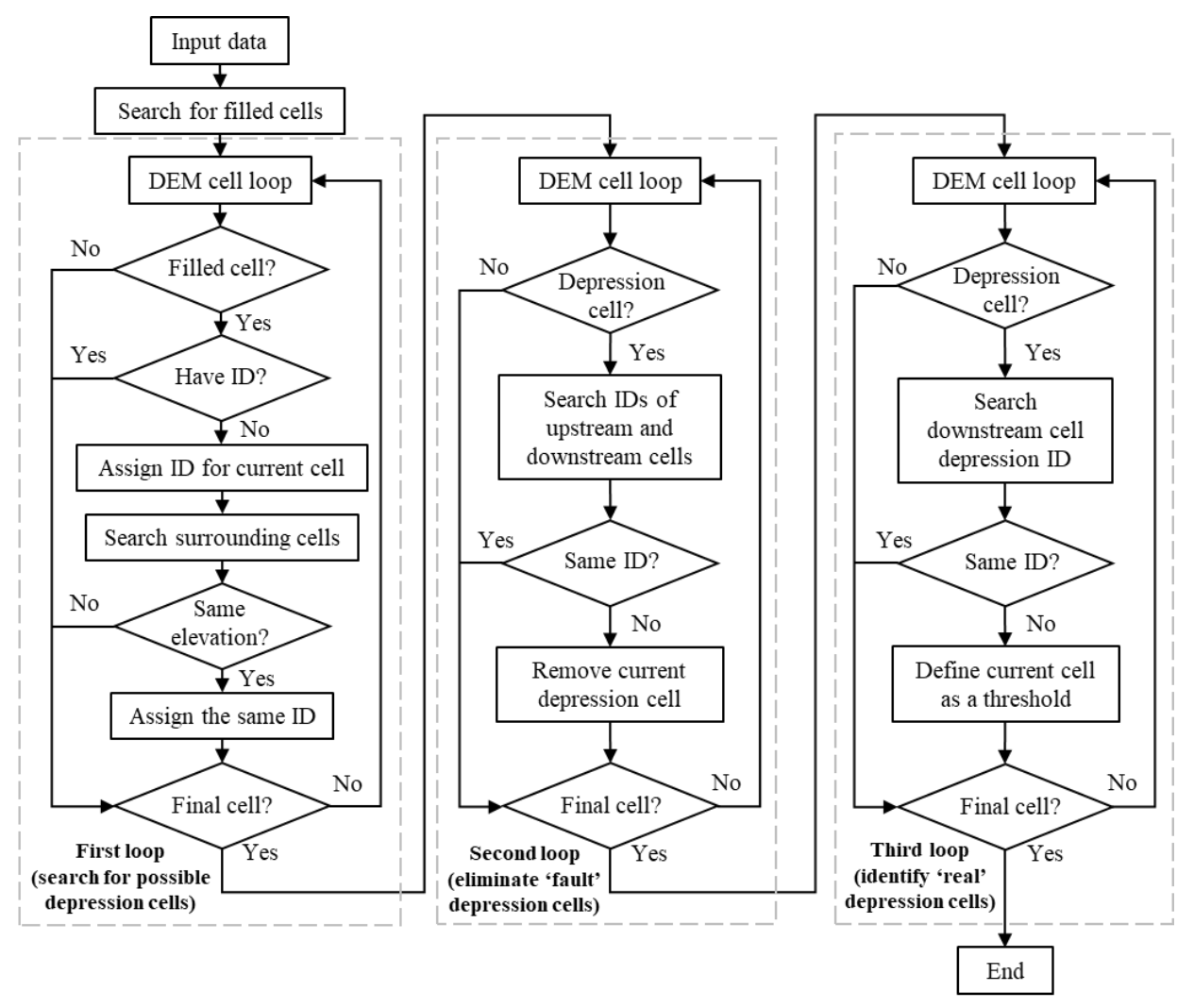

Figure 2. Flowchart of the depression identification module. 
Figure 3 shows the detailed depression delineation processes for an artificial surface. In this module, a searching process is implemented for all filled DEM cells by comparing the elevation differences between the original DEM and the fully filled DEM (Figures 2 and 3a). Each highest-level depression includes filled cells in an area and its associated threshold(s). Thus, after the filled cells are found, three cell loops are carried out to identify the overflow thresholds related to the filled cells. The first cell loop (Figure 2) is executed to find all possible depression cells and assign IDs to them based on the fully filled DEM (Figure 3b). In this loop, if one cell is a filled cell without ID, a new ID is generated and assigned to it and the same ID is given to its surrounding cells with an identical elevation. This loop continues until all possible depression cells are located. Since the first cell loop is only based on the elevations of the cells in a fully filled condition, some possible depression cells have the same elevation but no hydrologic connectivity with 'real' depression cells. For example, the elevation of cell J7 in Figure 3b equals 10, which is the same as the elevation of other cells in depression P3. However, cell $\mathrm{J} 7$ receives runoff from cell $\mathrm{J} 6$ and discharges to cell $\mathrm{J} 8$, while cell $\mathrm{I} 8$ receives the runoff generated from cells $\mathrm{H} 7$ and $\mathrm{H} 8$ and then transmits runoff to cell J9 (Figure 1c). Therefore, cell J7 is a 'fault' depression cell that has no hydrologic connectivity with other 'real' depression cells in P3.

\begin{tabular}{|c|c|c|c|c|c|c|c|c|c|c|}
\hline & 1 & 2 & 3 & 4 & 5 & 6 & 7 & 8 & 9 & 10 \\
\hline $\mathrm{A}$ & 50 & 49 & 50 & 47 & 47 & 47 & 47 & 47 & 47 & 50 \\
\hline $\mathrm{B}$ & 50 & 48 & 50 & 17 & 18 & 20 & 20 & 20 & 20 & 47 \\
\hline $\mathrm{C}$ & 50 & 47 & 16 & 46 & 46 & 46 & 20 & 20 & 20 & 47 \\
\hline $\mathrm{D}$ & 50 & 14 & 14 & 50 & 47 & 50 & 20 & 20 & 20 & 50 \\
\hline $\mathrm{E}$ & 50 & 14 & 14 & 48 & 50 & 49 & 48 & 47 & 20 & 48 \\
\hline $\mathrm{F}$ & 50 & 14 & 14 & 49 & 50 & 50 & 50 & 17 & 47 & 48 \\
\hline $\mathrm{G}$ & 50 & 14 & 14 & 50 & 46 & 45 & 50 & 16 & 50 & 50 \\
\hline $\mathrm{H}$ & 50 & 47 & 14 & 45 & 12 & 11 & 10 & 10 & 50 & 49 \\
\hline $\mathrm{I}$ & 50 & 50 & 48 & 13 & 48 & 48 & 50 & 10 & 48 & 49 \\
\hline $\mathrm{J}$ & 50 & 49 & 49 & 49 & 49 & 50 & 10 & 9 & 8 & 4 \\
\hline
\end{tabular}

(a)

\begin{tabular}{|c|c|c|c|c|c|c|c|c|c|c|}
\hline & & 2 & & & & & & & & \\
\hline & 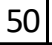 & 495 & 50 & 47 & 47 & 47 & 47| & 47 & & 5 \\
\hline & 4 & 485 & 50 & 7 & 8 & & & & \\
\hline & 0 & 4 . & 16 & 0 & 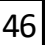 & 46 & & & & 4 \\
\hline & & & 50 & 7 & 50 & & & & \\
\hline & 50 & & & 48 & 50 & 49 & 48 & 47 & & 48 \\
\hline & 50 & & & 49 & 50 & 50 & 50 & 17 & 47 & 4 \\
\hline & 50 & & 2 & 50 & 46 & 45 & 50 & 16 & 50 & 5 \\
\hline & 50 & 47 & & 45 & 2 & 11 & $P$ & & 50 & 4 \\
\hline & 50 & 50 & 48 & 13 & 48 & 48 & 50 & & 48 & 4 \\
\hline & 50 & 49 & 49 & 49 & & 50 & & & & \\
\hline
\end{tabular}

(c)

\begin{tabular}{|c|c|c|c|c|c|c|c|c|c|c|}
\hline & 1 & 2 & 3 & 4 & 5 & 6 & & 8 & & \\
\hline & 50 & 49 & 50 & 47 & & & & 47 & & \\
\hline & 5 & & & & & & & & & \\
\hline & 50 & & 16 & & 46 & 40 & & P1 & & \\
\hline & 50 & & 30 & & 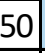 & & & & \\
\hline & 50 & & & 48 & 50 & 49 & 48 & 47 & & 4 \\
\hline & 50 & & & 49 & 0 & 50 & 50 & 17 & 47 & 4 \\
\hline & 50 & & & 50 & 6 & 45 & & 16 & 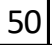 & \\
\hline & 50 & 4 & & 45 & 12 & 11 & $\mathrm{P} 3$ & & 50 & 4 \\
\hline & 50 & 50 & 48 & 13 & 48 & 48 & 50 & & 48 & 4 \\
\hline & 50 & 49 & 49 & 49 & 49 & 50 & & 9 & 8 & \\
\hline
\end{tabular}

(b)

\begin{tabular}{|c|c|c|c|c|c|c|c|c|c|c|}
\hline & 1 & & & & 5 & & & & & - \\
\hline & 50 & 495 & 50 & 47| & 47 & 47 & 7 & 47 & 47 & 5 \\
\hline & 50 & - & 50 & 7 & & & & \\
\hline & 50 & & & & 46 & & & & & \\
\hline & 50 & & 50 & 47 & 50 & & & & 50 \\
\hline & 50 & & & 48 & 50 & 49 & 48 & 47 & & $4 \varepsilon$ \\
\hline & 50 & & & 49 & 50 & 50 & & 17 & 47 & $4 \varepsilon$ \\
\hline & 50 & & & 50 & |46| & 45 & 50 & 16 & 50 & 5 \\
\hline & 50 & 47 & $\mathrm{~T} 3$ & 45 & 12 & 11 & $\mathrm{P3}$ & & 50 & 4 \\
\hline & 50 & 50 & 48 & 13 & 48 & 48 & 50 & $\mathrm{~T} 4$ & 48 & 4 \\
\hline & 50 & 49 & 49 & 49 & 49 & 50 & & & 8 & \\
\hline
\end{tabular}

(d)

Figure 3. Schematic diagrams for depression identification: (a) identification of the filled cells; (b) searching for possible depression cells; (c) elimination of 'fault' depression cells; and (d) identification of 'real' depression cells. Legend: $\square$ Depression cell $\square$ Depression threshold.

The second cell loop (Figure 2) was designed to remove the 'fault' cells like J7 (Figure 3c). In this loop, both the upstream and downstream cells of each possible depression cell are located based on the flow directions. If neither upstream cell nor downstream cell belong to the same depression with the possible depression cell, it is defined as a 'fault' depression cell and removed from its associated 
depression. After all 'real' depression cells are confirmed, the third cell loop (Figure 2) is initiated to find the thresholds of depressions and assign IDs to them. If a cell is a depression cell and its downstream cell is not a depression cell, it is defined as the threshold of its associated depression. Particularly, a depression may contain multiple thresholds. For example, both threshold T1 and threshold T2 in Figure $3 \mathrm{~d}$ belong to depression P1 (a two-threshold depression), while thresholds $\mathrm{T} 3$ and $\mathrm{T} 4$ respectively are the thresholds of their associated depressions P2 and P3 (two single-threshold depressions).

\subsubsection{Identification of Channels and Hydrologic Units}

The channel and HU identification module was executed to identify channels, PBUs, CBUs, and the connectivity between HUs. The method proposed by Jenson and Domingue [5] was used in this module to find channels in the fully filled condition, depending on a user-defined flow accumulation threshold and the flow directions (Figure 4). Figure 5a shows channel cells for the artificial surface (Figure 1a) when the flow accumulation threshold is set to 5 . Note that the channel cells within depressions were removed by overlaying the channels and depressions (Figure 4), and the IDs of remaining channel cells were determined by using the 'Stream Link' function in ArcGIS. Figure 5b shows the cells identified for four channels. To identify PBUs and CBUs, it is required to find the 'outlets' of depressions and channels, which are depression thresholds and channel ending points. Since all depression thresholds were found in the depression identification module, only channel ending points were searched by using a cell loop after the identification of channel cells within depressions (Figure 4). If a cell belongs to one channel and this channel does not have an ending point, the cell is defined as the channel ending point. On the other hand, if the cell belongs to one channel that already has an ending point, the flow accumulation of the cell and the current ending point are compared and the cell with a higher flow accumulation is set as the new channel ending point. This loop continues until all channel cells are searched and identified. Following this cell loop, the ending points of the four channels are identified (i.e., O1-O4 in Figure 5c). Since HUD-DC focuses on the watershed-scale surface delineation, an optional procedure can be executed to eliminate short channels based on a user-defined channel length threshold (Figure 4). The criteria to delete a channel were: (1) the length of a channel is shorter than the user-defined length threshold, and (2) the flow direction at the ending point of the channel does not point toward the outside (i.e., the ending point is an outlet). In this study, channel ending points were considered in the calculation of channel lengths. For example, the length of channel S2 was 2 (Figure 5b). If the channel length threshold was 3, S2 was removed from the channel cells, and cells F8 and G8 in channel S2 were then assigned as contributing cells of P3 (Figure 5d). For S4, however, although its length is the same as that of S2 (i.e., 2), it is still considered as a channel because cell J10 is the final outlet of the entire surface (Figure 5d). After all channel ending points were finalized, a channel loop was performed to assign continuous IDs for the channels and their ending points that follow the IDs of the depressions and their thresholds, respectively (Figure 4). For example, channel S1 and channel ending point $\mathrm{O} 1$ were changed to P4 and T5, respectively (Figure 5e). The delineation of HUs is the final key procedure in the channel and HU identification module. HUD-DC employs the 'Watershed' function in ArcGIS to handle the delineation of HUs by considering the depression thresholds and the channel ending points as pour points (Figures 4 and 5f). The IDs of the identified depressions and HUs were assigned to their associated HUs. 


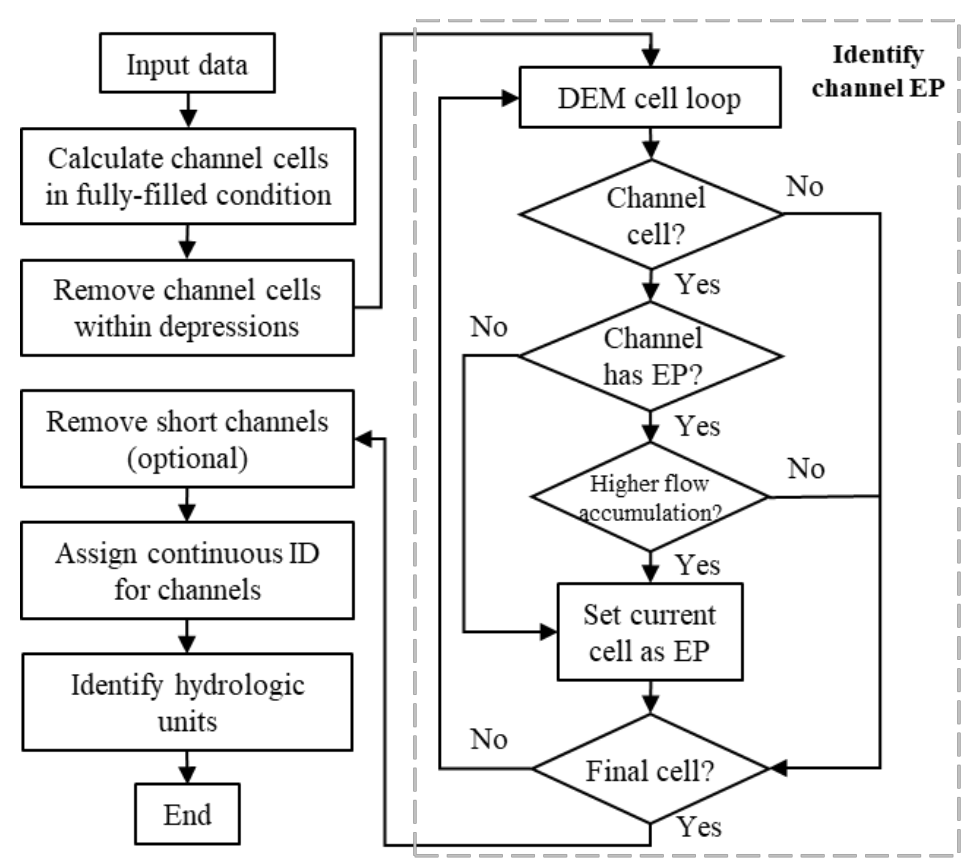

Figure 4. Flowchart of the channel and hydrologic unit (HU) identification module (EP: Ending point of a channel).

\begin{tabular}{|c|c|c|c|c|c|c|c|c|c|c|}
\hline $\mathrm{V}$ & 1 & 2 & 3 & 4 & 5 & 6 & 7 & 8 & 9 & 10 \\
\hline $\mathrm{A}$ & 50 & 49 & 50 & 47 & 47 & 47 & 47 & 47 & 47 & 50 \\
\hline $\mathrm{B}$ & 50 & 48 & 50 & 17 & 18 & 20 & 20 & 20 & 20 & 47 \\
\hline $\mathrm{C}$ & 50 & 47 & 16 & 46 & 46 & 46 & 20 & 20 & 20 & 47 \\
\hline $\mathrm{D}$ & 50 & 14 & 14 & 50 & 47 & 50 & 20 & 20 & 20 & 50 \\
\hline $\mathrm{E}$ & 50 & 14 & 14 & 48 & 50 & 49 & 48 & 47 & 20 & 48 \\
\hline $\mathrm{F}$ & 50 & 14 & 14 & 49 & 50 & 50 & 50 & 17 & 47 & 48 \\
\hline $\mathrm{G}$ & 50 & 14 & 14 & 50 & 46 & 45 & 50 & 16 & 50 & 50 \\
\hline $\mathrm{H}$ & 50 & 47 & 14 & 45 & 12 & 11 & 10 & 10 & 50 & 49 \\
\hline $\mathrm{I}$ & 50 & 50 & 48 & 13 & 48 & 48 & 50 & 10 & 48 & 49 \\
\hline $\mathrm{J}$ & 50 & 49 & 49 & 49 & 49 & 50 & 10 & 9 & 8 & 4 \\
\hline
\end{tabular}

(a)

\begin{tabular}{|c|c|c|c|c|c|c|c|c|c|c|}
\hline & 1 & 2 & & 4 & 5 & 6 & & 8 & 9 & 10 \\
\hline A & 50 & 49 & 50 & 40 & 47 & 47 & 47 & 47 & 47 & 50 \\
\hline B & 50 & \begin{tabular}{ll|l}
5 & 5
\end{tabular} & 50 & s1 & S1 & $\mathrm{T} 1$ & \multirow{3}{*}{\multicolumn{2}{|c|}{ P1 }} & & 47 \\
\hline C & 50 & 47 & D1 & 46 & 46 & 46 & & & & 47 \\
\hline $\mathrm{D}$ & 50 & \multirow{4}{*}{\multicolumn{2}{|c|}{ P2 }} & 50 & 47 & 50 & & & & 50 \\
\hline$E$ & 50 & & & 48 & 50 & 49 & 48 & 47 & $\mathrm{~T} 2$ & 48 \\
\hline$r$ & 50 & & & 49 & 50 & 50 & 50 & 17 & 47 & 48 \\
\hline $\mathrm{G}$ & 50 & & & 50 & 46 & 45 & & 16 & 50 & 50 \\
\hline $\mathrm{H}$ & 50 & 47 & T3 & 45 & $\mathrm{S3}$ & 03 & $\vec{P}$ & & 50 & 49 \\
\hline 1 & 50 & 50 & 18 & 53 & 48 & 48 & 50 & T4 & 48 & 49 \\
\hline $\mathrm{J}$ & 50 & 49 & 19 & 49 & 49 & 50 & & 9 & S4 & $\mathrm{O} 4$ \\
\hline
\end{tabular}

(d)

\begin{tabular}{|c|c|c|c|c|c|c|c|c|c|c|}
\hline & 1 & 2 & & 4 & & 6 & 7 & & & 10 \\
\hline A & 50 & 49 & 50 & 47 & 47 & 47 & 47 & 47 & 47 & 50 \\
\hline B & 50 & 48 & 50 & $\mathrm{~S} 1$ & $\mathrm{S1}$ & $\mathrm{T} 1$ & \multirow{3}{*}{\multicolumn{3}{|c|}{ P1 }} & 47 \\
\hline$C$ & 50 & 47| & S1 & 46 & 46 & 46 & & & & $|47|$ \\
\hline $\mathrm{D}$ & 50 & \multirow{4}{*}{\multicolumn{2}{|c|}{ P2 }} & 50 & 17 & 50 & & & & 50 \\
\hline$E$ & 50 & & & 48 & 50 & 49 & 48 & 47 & $\mathrm{~T} 2$ & 48 \\
\hline$F$ & 50 & & & 49 & 50 & 50 & 50 & $\mathrm{~S} 2$ & 47 & 48 \\
\hline $\mathrm{G}$ & 50 & & & 50 & 46 & 45 & 50 & $\mathrm{~S} 2$ & 50 & 50 \\
\hline $\mathrm{H}$ & 50 & 47 & T3 & 45 & $\mathrm{S3}$ & $\mathrm{S3}$ & $\mathrm{P}$ & 3 & 50 & 49 \\
\hline 1 & 50 & 50 & 48 & S3 & 48 & 48 & 50 & T4 & 48 & 49 \\
\hline $\bar{J}$ & 50 & & 49 & 49 & 49 & 50 & & 9 & S4 & 54 \\
\hline
\end{tabular}

(b)

\begin{tabular}{|c|c|c|c|c|c|c|c|c|c|c|}
\hline & 1 & 2 & & 4 & 5 & 6 & 7 & 8 & 9 & 10 \\
\hline A & 50 & 495 & 0 & 17 & 47 & 47 & 47 & 47 & 47 & 50 \\
\hline B & 50 & 48 & 0 & 24 & P4 & T1 & \multirow{3}{*}{\multicolumn{3}{|c|}{ P1 }} & 47 \\
\hline$C$ & 50 & & 5 & 46 & 46 & 46 & & & & 47 \\
\hline $\mathrm{D}$ & 50 & \multirow{4}{*}{\multicolumn{2}{|c|}{ P2 }} & 50 & 47 & 50 & & & & 50 \\
\hline $\mathrm{E}$ & 50 & & & 48 & 50 & 49 & 48 & 47 & $\mathrm{~T} 2$ & 48 \\
\hline$F$ & 50 & & & 49 & 50 & 50 & 50 & 17 & 47 & 48 \\
\hline $\mathrm{G}$ & 50 & & & 50 & 46 & 45 & 50 & 16 & 50 & 50 \\
\hline $\mathrm{H}$ & 50 & 47 & & 45 & P5 & T6 & & 3 & 50 & 49 \\
\hline I & 50 & 50 & 18 & 5 & 48 & 48 & 50 & T4 & 48 & 49 \\
\hline J & 50 & 49 & & 49 & 49 & 50 & 10 & 9 & & $\mathrm{T7}$ \\
\hline
\end{tabular}

(e)

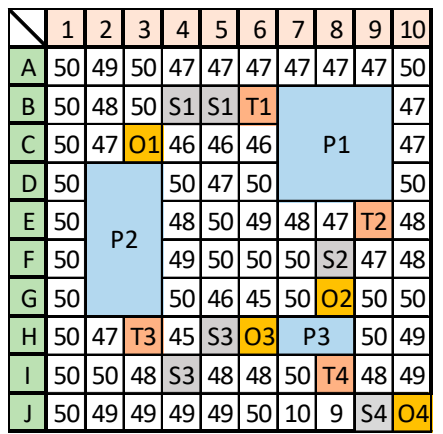

(c)

\begin{tabular}{|c|c|c|c|c|c|c|c|c|c|}
\hline & 1 & \begin{tabular}{l|l}
2 & 3 \\
\end{tabular} & 4 & 5 & $\epsilon$ & 7 & 8 & & 10 \\
\hline $\mathrm{A}$ & 50 & & 47 & \begin{tabular}{l|l|l}
7 & 4 \\
\end{tabular} & 4 & 47 & 47 & 4 & 50 \\
\hline B & 501 & $4 8 \longdiv { 5 }$ & P & & $4 \mathrm{~T}$ & & \multirow{3}{*}{ P1 } & & 47 \\
\hline C & 50 & $47 \mathrm{~T}$ & 46 & \begin{tabular}{l|l}
6 & 4 \\
\end{tabular} & 54 & & & & 47 \\
\hline$D$ & 50 & \multirow{4}{*}{$\mathrm{P} 2$} & $5 c$ & 4 & 5 & & & & 50 \\
\hline$E$ & 50 & & $4 \varepsilon$ & 5 & 4 & $9 \mid 48$ & 47 & $\mathrm{~T}$ & 248 \\
\hline$F$ & 50 & & 45 & 915 & & 50 & 17 & & 7148 \\
\hline $\mathrm{G}$ & 50 & & & 0 & & 5,50 & 16 & 5 & 50 \\
\hline $\mathrm{H}$ & 50 & \begin{tabular}{l|l|l}
47 &
\end{tabular} & 45 & 5 P & \begin{tabular}{|l|l}
5 \\
\end{tabular} & & P3 & 5 & 49 \\
\hline I & 50 & 504 & 3 & \begin{tabular}{l|l}
5 & 4
\end{tabular} & & 85 & TS & 4 & 349 \\
\hline J & 50 & \begin{tabular}{l|l}
49 & 4 \\
\end{tabular} & 4 & & & \begin{tabular}{l|l}
0 & 10 \\
\end{tabular} & 9 & & 5 \\
\hline
\end{tabular}

(f)

Figure 5. Schematic diagrams for delineation of channels and hydrologic units: (a) searching for channel cells, (b) overlay of channel cells and depression cells, (c) identification of channel ending points, (d) elimination of short channels, (e) assignment of continuous IDs, and (f) delineation of hydrologic unit boundaries. Legend: $\square$ Depression cell $\square$ Depression threshold $\square$ Channel cell $\square$ Channel ending point - - - Hydrologic unit boundary. 


\subsubsection{Output Data and Format}

Based on the input data, HUD-DC generates a set of output files related to HUs and their connectivity. Since HUD-DC is an ArcGIS-based algorithm, the output files of HUD-DC are in either raster or vector format, which facilitates the related hydrologic modeling. Two major types of output files include: (1) polygon files that store depression and HU characteristics and (2) point files that store the information about depression thresholds and channel ending points. The polygon files related to depressions and HUs contain maximum depression storage (MDS), maximum ponding area (MPA), HU area, and the threshold numbers of HUs. The point files store not only the IDs of depression thresholds and channel ending points but also the IDs of upstream and downstream HUs. In this way, the hydrologic connectivity between HUs can be saved in these files. Furthermore, channel lengths and slopes are also saved in the point files related to the channel ending points.

\subsection{Study Area and Testing of HUD-DC}

In this study, the Upper Pipestem Creek watershed in North Dakota (Figure 6) was selected to test the performance of HUD-DC in surface delineation. As the contributing area of the USGS 06469400 Pipestem creek gauge station $\left(47^{\circ} 10^{\prime} 03^{\prime \prime} \mathrm{N}, 98^{\circ} 58^{\prime} 07^{\prime \prime} \mathrm{W}\right)$, the study area covers an area of $1668.12 \mathrm{~km}^{2}$, including parts of four counties in North Dakota (i.e., Wells, Foster, Kidder, and Stutsman counties) (Figure 6). Based on the 2011 NLCD (National Land Cover Database), the study area is mainly covered by cultivated crops $(42.89 \%)$, herbaceous $(26.01 \%)$, and pasture $(14.81 \%)$. Moreover, the open water and emergent herbaceous wetlands account for $6.28 \%$ and $5.89 \%$, respectively.

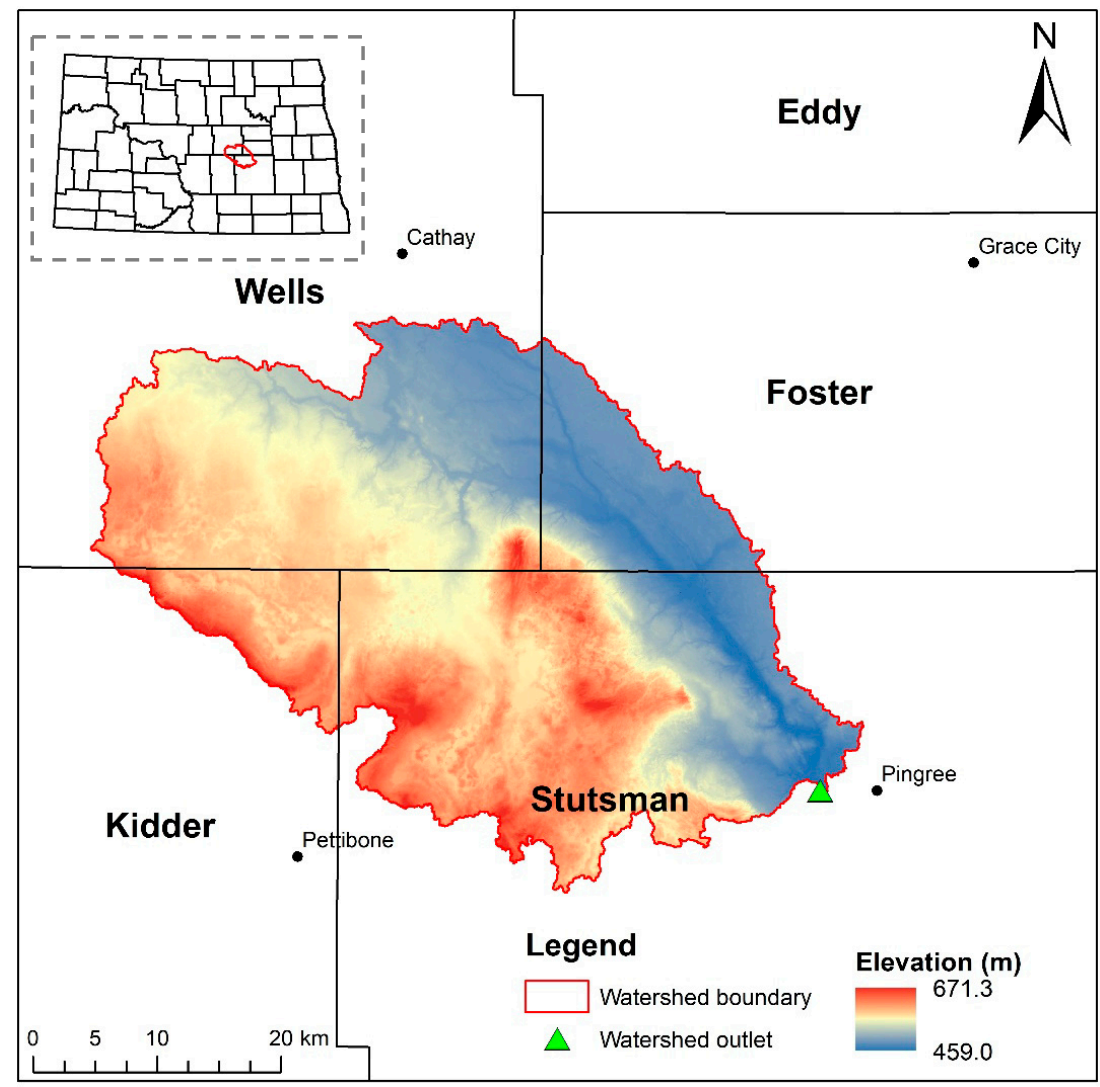

Figure 6. Geographical location of the Upper Pipestem Creek watershed.

Since numerous depressions are scattered across the study area, analyzing depressions and their connectivity is critical to modeling of hydrologic processes in this watershed. An original 30-m DEM of the watershed was downloaded from the USGS National Map Viewer and used as the input data 
of HUD-DC for surface delineation. Arc Hydro was also applied to the study area and compared with HUD-DC in delineation of depressions. In addition, the similarities and differences between the two methods were analyzed according to the surface delineation results and the underlying methodologies. Based on the delineation results of HUD-DC, topographic characteristics of the study area were analyzed to highlight the significance of depressions.

The existence of artifacts in DEM is a critical issue in depression identification. Numerous insignificant depressions can be generated from the original DEM [27]. In this study, the original DEM was pre-filled. Specifically, a series of incremental water depths were applied to fill depressions, and meanwhile the variations in topographic characteristics (e.g., MDS, MPA, and number of depressions) with the filling depths were analyzed, from which a filling threshold was identified to ensure that the artifacts were effectively removed without significantly changing the topographic characteristics and hydrologic connectivity of the study area.

\section{Results}

\subsection{Watershed Delineation and Topographic Analysis}

Figure 7a,b, respectively, shows the surface delineation results from Arc Hydro and HUD-DC based on the original DEM of the Upper Pipestem Creek watershed. For Arc Hydro, because channels were not considered in the 'Depression Evaluation' tool, only depressions and their associated contributing areas (CAs) were identified for the watershed (Figure 7a). Compared with Arc Hydro, HUD-DC extracted the channel drainage network of the watershed from the DEM (Figure 7b), identified CAs for all depressions and channels, and calculated the connectivity between HUs.

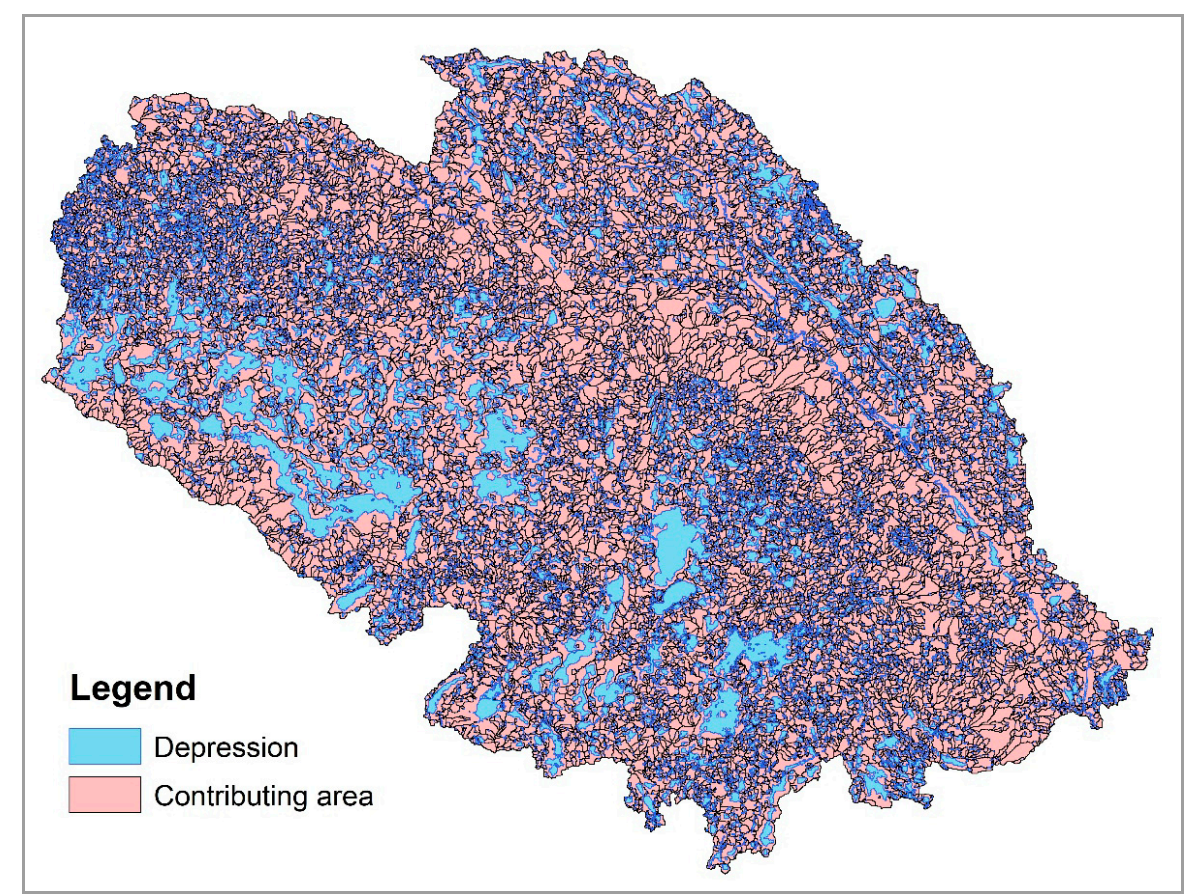

(a)

Figure 7. Cont. 


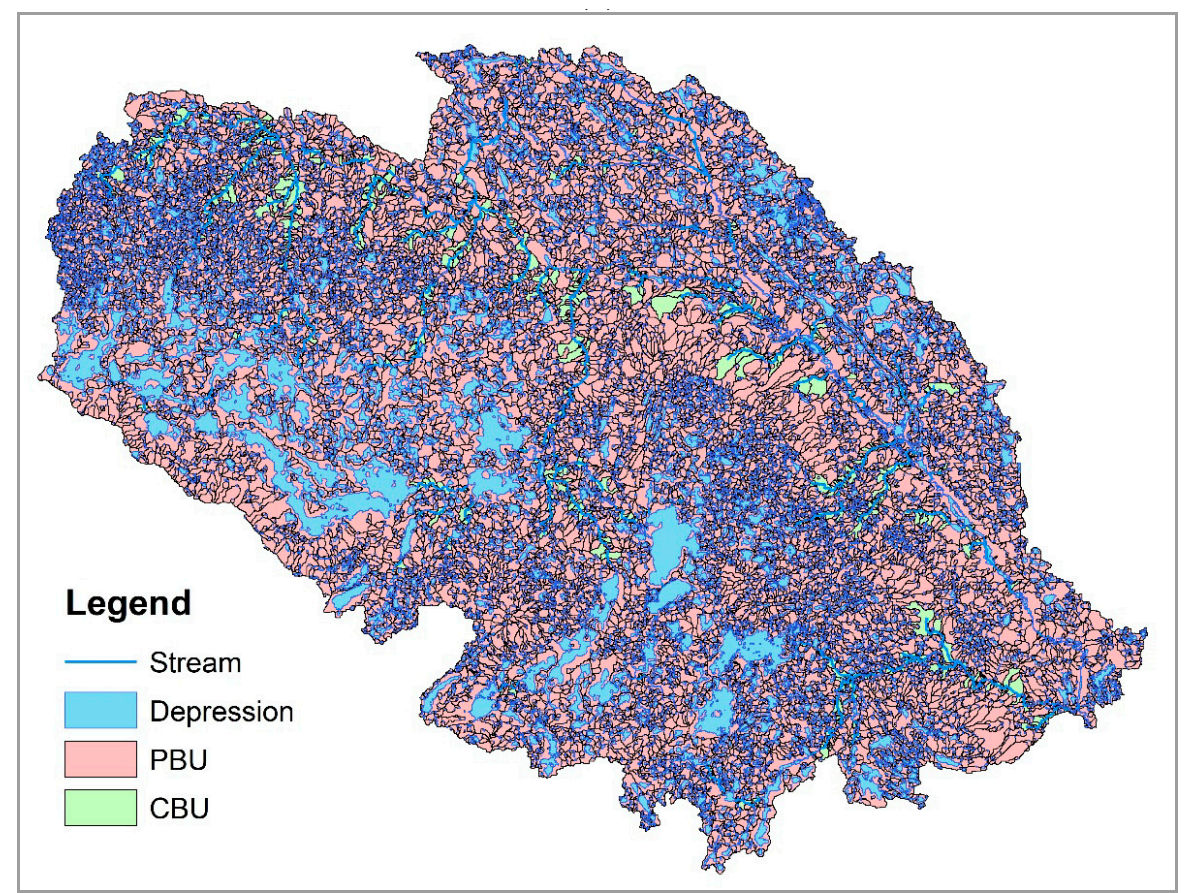

(b)

Figure 7. Surface delineation results of (a) Arc Hydro; and (b) HUD-DC. (PBU: puddle-based unit; CBU: channel-based unit).

It can be observed from the delineation results that depressions dominate the study area, and they divide the entire watershed into numerous relatively independent HUs, which causes hydrologic disconnectivity. The depressions delineated by both methods have a similar distribution: numerous small depressions are scattered across the watershed, and large depressions are mainly located in the southwest of the study area (Figure 7). The channels identified by HUD-DC are mainly located in the middle of the watershed, forming a drainage network that connect different depressions. Specifically, 17,827 depressions were identified by HUD-DC. The MDS and MPA of the entire watershed are $404.33 \times 10^{6} \mathrm{~m}^{3}$ and $292.04 \mathrm{~km}^{2}$, respectively (Table 1). However, Arc Hydro yielded more depressions and smaller MPA than HUD-DC (Table 1).

Table 1. Comparison of the delineation results from Arc Hydro and HUD-DC. (MDS: maximum depression storage; MPA: maximum ponding area; PBU: puddle-based unit in HUD-DC; DCA: depression contributing area in Arc Hydro).

\begin{tabular}{|c|c|c|c|c|c|}
\hline \multirow{2}{*}{ Method/Tool } & \multirow{2}{*}{$\begin{array}{c}\text { Number of } \\
\text { Depressions }\end{array}$} & \multirow{2}{*}{$\frac{\text { MDS }}{\left(10^{6} \mathrm{~m}^{3}\right)}$} & \multirow{2}{*}{$\frac{\text { MPA }}{\left(\mathrm{km}^{2}\right)}$} & \multicolumn{2}{|c|}{ PBU or DCA } \\
\hline & & & & $\left(\mathrm{km}^{2}\right)$ & $(\%)$ \\
\hline Arc Hydro & 18,190 & 404.33 & 267.47 & 1668.12 & 100.00 \\
\hline HUD-DC & 17,827 & 404.33 & 292.04 & 1597.22 & 95.19 \\
\hline
\end{tabular}

\subsection{Identification of Filling Threshold for Removing Artifacts}

As mentioned previously, numerous small depressions, including artifacts, were identified in the delineation process. To identify the filling threshold for removing those artifacts, the original DEM was pre-filled gradually with a set of incremental water depths and the variations in topographic characteristics (e.g., MDS, MPA, number of depressions) were examined under different filling conditions. Figure 8 shows the variations of the normalized maximum depression storage (NMDS), normalized maximum ponding area (NMPA) and normalized number of depressions (NDN) with the increase of the filling depth. The NMDS, NMPA, and NDN in a filling condition are defined as the ratios of the MDS, the MPA, and the number of depressions under such a filling condition 
to their corresponding values under the unfilled condition. An overall decreasing pattern can be observed for the three dimensionless topographic parameters (Figure 8). NDN exhibits the steepest decrease, while NMPA and NMDS decrease gradually with an increase of the filling depth (Figure 8). From Figure 8, four stages can be identified in the filling process: (1) removal of the artifacts (filling depth $=0-0.1 \mathrm{~m})$, (2) filling small depressions (filling depth $=0.1-1.0 \mathrm{~m})$, (3) filling medium depressions (filling depth $=1-5 \mathrm{~m}$ ), and (4) filling large depressions (filling depth $=5-13 \mathrm{~m}$ ). In the first stage, NMDS and NMPA decreased by 0.007 and 0.178 , respectively (Figure 8). However, NDN decreased by 0.645 , indicating that the depressions filled during this stage are mainly extremely small depressions that almost have no storage capacities. Thus, these depressions can be considered as artifacts and $0.1 \mathrm{~m}$ can be used as the filling threshold to control most artifacts for this study area. During the second stage, the decreasing rates of NMPA and NDN gradually became smaller. These phenomena are due to the filling of small depressions, which are the major depressions in quantity, but have limited storages and areas in the watershed. The medium depressions are fully filled in the third stage. During this period, NMDS decreased from 0.904 to 0.298 with a relatively stable rate, but NMPA and NDN still show a decreasing trend (Figure 8). In general, the decreasing rates of NMPA and NMDS are higher than that of NDN, which indicates that the medium depressions have relatively larger storages and areas, but their number is limited. When the filling depth reached $5 \mathrm{~m}, \mathrm{NDN}$ equaled 0.002 (Figure 8), implying that only a few large depressions were not fully filled in the study area at the fourth stage. Because the depressions with substantial storages and areas were fully filled, hierarchical drops of NMDS and NMPA can be observed during the filling process in this stage.

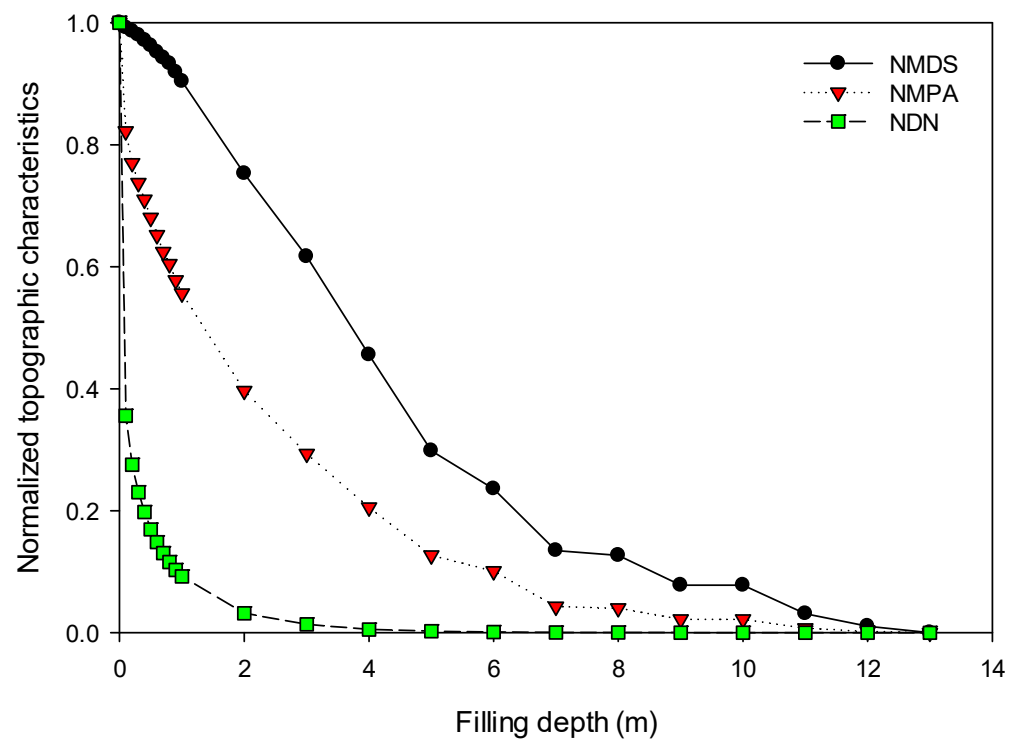

Figure 8. Variations of topographic characteristics with different filling depths. (NMDS: normalized maximum depression storage; NMPA: normalized maximum ponding area; NDN: normalized number of depressions).

Figure 9 shows the spatial distributions of depressions and HUs and the variations of hydrologic connectivity with an increase of filling depths. Compared with the unfilled condition (Figure $7 \mathrm{~b}$ ), when depressions were filled with a water depth of $0.1 \mathrm{~m}$, more CBUs were developed in the middle of the watershed, but the hydrologic connectivity was still not well developed due to the existence of small depressions (Figure 9a). In this condition, the percentages of PBUs and CBUs for the entire area were $86.90 \%$ and $13.10 \%$ (Table 2), respectively, indicating that depressions still dominated the study area. When the filling depth reached $1 \mathrm{~m}$, both PBUs and CBUs accounted for almost half of the total watershed area (Table 2) and a relatively complete channel network emerged in the northeast of the watershed (Figure 9b). However, because two large PBUs (i.e., the PBUs in the rectangle areas 
in Figure 9b) broke the connectivity between CBUs, the CA of the watershed outlet was still limited. When depressions were filled by a 5-m depth, CBUs dominated the study area and accounted for $90.30 \%$ of the entire watershed area. Figure $9 \mathrm{c}$ illustrates that almost the entire watershed has a well-developed connection to its associated outlet, except for several PBUs in the southwest and south of the watershed.

Table 2. Topographic characteristics of the Upper Pipestem Creek watershed with the original DEM filled by a depth of $0.1 \mathrm{~m}, 1.0 \mathrm{~m}$, and $5.0 \mathrm{~m}$. (MDS: maximum depression storage; MPA: maximum ponding area; PBU: puddle-based unit; CBU: channel-based unit).

\begin{tabular}{|c|c|c|c|c|c|c|}
\hline \multirow{2}{*}{$\begin{array}{c}\text { Filling Depth } \\
\text { (m) }\end{array}$} & \multirow{2}{*}{$\frac{\text { MDS }}{\left(10^{6} \mathrm{~m}^{3}\right)}$} & \multirow{2}{*}{$\begin{array}{l}\text { MPA } \\
\left(\mathrm{km}^{2}\right)\end{array}$} & \multicolumn{2}{|c|}{ PBU } & \multicolumn{2}{|c|}{ CBU } \\
\hline & & & $\left(\mathrm{km}^{2}\right)$ & $(\%)$ & $\left(\mathrm{km}^{2}\right)$ & $(\%)$ \\
\hline 0.1 & 401.19 & 240.09 & 1449.51 & 86.90 & 218.61 & 13.10 \\
\hline 1.0 & 365.55 & 162.47 & 912.26 & 54.69 & 755.86 & 45.31 \\
\hline 5.0 & 120.56 & 36.97 & 161.82 & 9.70 & 1506.30 & 90.30 \\
\hline
\end{tabular}

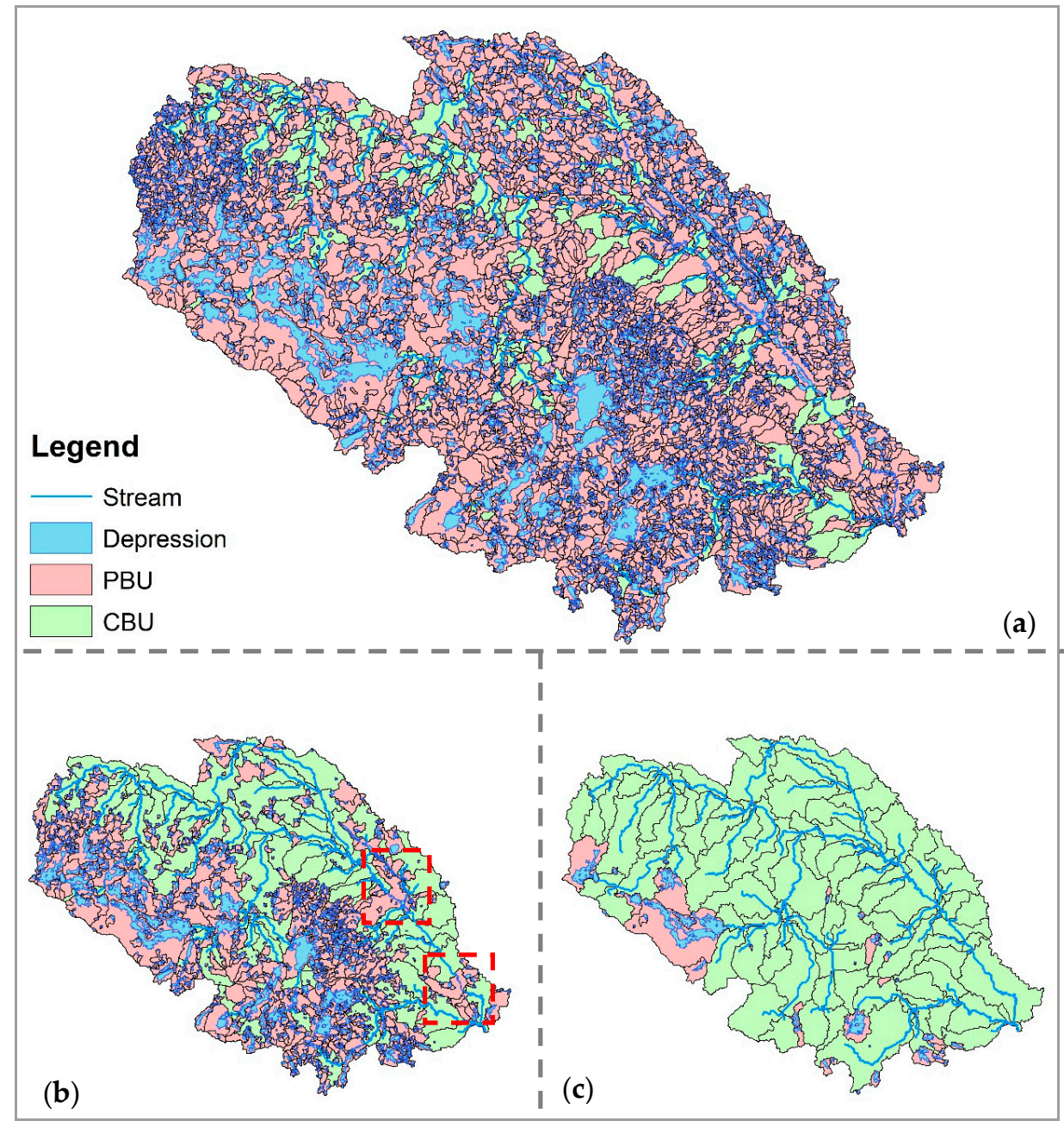

Figure 9. Spatial distributions of depressions and hydrologic units with the original DEM filled by a depth of (a) $0.1 \mathrm{~m}$; (b) $1 \mathrm{~m}$; and (c) $5 \mathrm{~m}$. (PBU: puddle-based unit; CBU: channel-based unit; rectangle frames: PBUs that break the connectivity of CBUs).

\section{Discussions}

Surface depressions increase the complexity of hydrologic connectivity in depression-dominated areas. However, they are usually removed in traditional delineation methods. Two approaches are 
often utilized to handle depressions in surface delineation: identifying the highest-level depressions (e.g., [21,22]), and identifying depressions across all hierarchical levels (e.g., [23,25]). HUD-DC developed in this study not only identifies surface depressions, but also delineates channels and quantifies the connectivity between depressions and channels. Differently from the second approach that delineates all-level depressions at smaller spatial scales, HUD-DC focuses on improving the efficiency of surface delineation and revealing hydrologic connectivity at a larger watershed scale.

In the comparison of the delineation results from Arc Hydro and HUD-DC, the differences in MPA and the number of depressions can be attributed to the difference in the definitions of depression in the two methods. In Arc Hydro, each filled area is defined as a depression, and depression overflow thresholds are not considered. In HUD-DC, however, depression thresholds are also identified for all filled areas. If two filled areas (i.e., depressions) share the same threshold, they merge, forming one higher-level depression. Therefore, the number of depressions calculated by HUD-DC is smaller than that from Arc Hydro. In addition, the MPA calculated by HUD-DC is the summation of all filled areas and the threshold areas. Consequently, the MPA obtained by HUD-DC is larger than that from Arc Hydro. The delineation results of both methods highlight the importance of depressions in watershed modeling for depression-dominated areas [18-20].

The hydrologic connectivity of a surface exhibits a dynamic and hierarchical variation pattern during the filling of depressions $[16,19]$. The discussion on depression characteristics during the filling process in Section 3.2 indicates that removing artifacts did improve the hydrologic connectivity in the study area without significant changes in NMDS. The percentage of PBUs in the study area decreased from $95.19 \%$ to $86.90 \%$. However, the NMDS only decreased by 0.007 . It was also found that small and medium depressions dominated the influence on the variations of hydrologic connectivity in the study area. Filling the small and medium depressions resulted in a significant improvement in hydrologic connectivity. For large depressions, since a significant amount of runoff water is required to fully fill them, they can be considered as a 'dead zone' in the hydrologic connectivity analyses and hydrologic simulations under most circumstances. Additionally, the spatial distribution of depressions also influenced the hydrologic connectivity of the study area.

Since HUD-DC is designed for delineating HUs at a watershed scale, the internal low-level depressions in PBUs are not considered. In addition, three cell loops are implemented for the identification of depression thresholds in the current algorithm, which may influence the efficiency of HUD-DC, especially for very large watersheds.

\section{Conclusions}

In this study, HUD-DC was developed to investigate hydrologic connectivity in depressiondominated areas (e.g., PPR) and provides detailed topographic characteristics for hydrologic models. To test the performance of HUD-DC in surface delineation, it was applied to the Upper Pipestem Creek watershed in North Dakota and compared with the 'Depression Evaluation' function in Arc Hydro. The topographic characteristics of the study area under the unfilled condition were analyzed. Particularly, HUD-DC was utilized to evaluate the changes in topographic features under different filling conditions, which enabled the identification of the filling threshold to effectively remove artifacts in the DEM.

In the comparison with Arc Hydro, HUD-DC yielded similar results, demonstrating its accuracy in the surface delineation and identification of depressions. The differences between the two methods were mainly associated with the definition of depressions and the depression searching procedure. Numerous depressions were scattered across the study area and the percentage of PBUs was $95.19 \%$, which emphasized the significance of depressions in hydrologic connectivity in this depression-dominated watershed. In the analyses of topographic characteristics for various filling depths, four filling stages were identified based on the variation trends of NMDS, NMPA, and NDN, and dynamic variations of hydrologic connectivity in the study area were observed. For the selected watershed, a depth of $0.1 \mathrm{~m}$ was selected as the filling threshold that can be used to control or remove most artifacts in the 
DEM. Although HUD-DC was successfully applied to the Upper Pipestem Creek watershed for surface delineation, more tests would be helpful to improve its efficiency and demonstrate its applicability, especially for large-scale watersheds.

Author Contributions: All authors contributed equally to this work, including the related research and writing. All authors have read and agreed to the published version of the manuscript.

Funding: This material is based upon work supported by the National Science Foundation under Grant No. NSF EPSCoR Award IIA-1355466. The North Dakota Water Resources Research Institute also provided partial financial support in the form of a graduate fellowship for the first author.

Conflicts of Interest: The authors declare no conflict of interest. The funding agencies had no role in the design of the study; in the collection, analyses, or interpretation of data; in the writing of the manuscript, and in the decision to publish the results.

\section{References}

1. Hay, L.; Norton, P.; Viger, R.; Markstrom, S.; Regan, R.S.; Vanderhoof, M. Modeling Surface-Water Depression Storage in a Prairie Depression Region. Hydrol. Process. 2018, 32, 462-479. [CrossRef]

2. Vanderhoof, M.K.; Alexander, L.C.; Todd, M.J. Temporal and Spatial Patterns of Wetland Extent Influence Variability of Surface Water Connectivity in the Prairie Pothole Region, United States. Landsc. Ecol. 2016, 31, 805-824. [CrossRef]

3. Garbrecht, J.; Martz, L.W. TOPAZ: An Automated Digital Landscape Analysis Tool for Topographic Evaluation, Drainage Identification, Watershed Segmentation and Subcatchment Parameterization: TOPAZ User Manual; Grazinglands Research Laboratory, USDA Agricultural Research Services: El Reno, OK, USA, 1997.

4. Jasiewicz, J.; Metz, M. A New GRASS GIS Toolkit for Hortonian Analysis of Drainage Networks. Comput. Geosci. 2011, 37, 1162-1173. [CrossRef]

5. Jenson, S.K.; Domingue, J.O. Extracting Topographic Structure from Digital Elevation Data for Geographic Information System Analysis. Photogramm. Eng. Remote Sens. 1988, 54, 1593-1600.

6. Martínez-Casasnovas, J.A.; Stuiver, H.J. Automated Delineation of Drainage Networks and Elementary Catchments from Digital Elevation Models. Int. J. Appl. Earth Obs. Geoinf. 1998, 3, 198-208.

7. O'Callaghan, J.F.; Mark, D.M. The Extraction of Drainage Networks from Digital Elevation Data. Comput. Graph. Image Process. 1984, 28, 323-344. [CrossRef]

8. Arnold, N. A New Approach for Dealing with Depressions in Digital Elevation Models when Calculating Flow Accumulation Values. Prog. Phys. Geogr. 2010, 34, 781-809. [CrossRef]

9. Shaw, D.A.; Pietroniro, A.; Martz, L.W. Topographic Analysis for the Prairie Pothole Region of Western Canada. Hydrol. Process. 2013, 27, 3105-3114. [CrossRef]

10. McCormack, J.E.; Gahegan, M.N.; Roberts, S.A.; Hogg, J.; Hoyle, B.S. Feature-Based Derivation of Drainage Networks. Int. J. Geogr. Inf. Sci. 1993, 7, 263-279. [CrossRef]

11. Rieger, W. Automated River Line and Catchment Area Extraction from DEM Data. Int. Arch. Photogramm. Remote Sens. 1993, 29, 642.

12. Martz, L.W.; Garbrecht, J. The Treatment of Flat Areas and Depressions in Automated Drainage Analysis of Raster Digital Elevation Models. Hydrol. Process. 1998, 12, 843-855. [CrossRef]

13. Soille, P. Optimal Removal of Spurious Pits in Grid Digital Elevation Models. Water Resour. Res. 2004, 40, W12509. [CrossRef]

14. Huang, P.C.; Lee, K.T. A Simple Depression-Filling Method for Raster and Irregular Elevation Datasets. J. Earth Syst. Sci. 2015, 124, 1653-1665. [CrossRef]

15. Chu, X.; Yang, J.; Chi, Y.; Zhang, J. Dynamic Puddle Delineation and Modeling of Puddle-To-Puddle Filling-Spilling-Merging-Splitting Overland Flow Processes. Water Resour. Res. 2013, 49, 3825-3829. [CrossRef]

16. Chu, X. Delineation of Pothole-Dominated Wetlands and Modeling of Their Threshold Behaviors. J. Hydrol. Eng. 2017, 22, D5015003. [CrossRef]

17. Wang, N.; Zhang, X.; Chu, X. New Model for Simulating Hydrologic Processes Under Influence of Surface Depressions. J. Hydrol. Eng. 2019, 24, 04019008. [CrossRef] 
18. McCauley, L.A.; Anteau, M.J. Generating Nested Wetland Catchments with Readily-Available Digital Elevation Data May Improve Evaluations of Land-Use Change on Wetlands. Wetlands 2014, 34, 1123-1132. [CrossRef]

19. Grimm, K.; Chu, X. Modeling of Spatiotemporal Variations in Runoff Contribution Areas and Analysis of Hydrologic Connectivity. Land. Degrad Dev. 2018, 29, 2629-2643. [CrossRef]

20. Tahmasebi Nasab, M.; Singh, V.; Chu, X. SWAT Modeling for Depression-Dominated Areas: How Do Depressions Manipulate Hydrologic Modeling? Water 2017, 9, 58. [CrossRef]

21. Temme, A.J.; Schoorl, J.M.; Veldkamp, A. Algorithm for Dealing with Depressions in Dynamic Landscape Evolution Models. Comput. Geosci. 2006, 32, 452-461. [CrossRef]

22. Maidment, D.R. ArcHydro: GIS for Water Resour; ESRI Press: Redlands, CA, USA, 2002.

23. Chu, X.; Zhang, J.; Chi, Y.; Yang, J. An Improved Method for Watershed Delineation and Computation of Surface Depression Storage. In Watershed Management Conference 2010; Potter, K.W., Frevert, D.K., Eds.; American Society of Civil Engineers (ASCE): Reston, VA, USA, 2010; pp. 1113-1122.

24. Yang, J.; Chu, X. A New Modeling Approach for Simulating Microtopography-Dominated, Discontinuous Overland Flow on Infiltrating Surfaces. Adv. Water Resour. 2015, 78, 80-93. [CrossRef]

25. Tahmasebi Nasab, M.; Zhang, J.; Chu, X. A New Depression-Dominated Delineation (D-Cubed) Method for Improved Watershed Modeling. Hydrol. Process. 2017, 31, 3364-3378. [CrossRef]

26. Liu, X.; Wang, N.; Shao, J.; Chu, X. An Automated Processing Algorithm for Flat Areas Resulting from DEM Filling and Interpolation. ISPRS Int. J. Geo-Inf. 2017, 6, 376. [CrossRef]

27. Tarboton, D.G.; Bras, R.L.; Rodriguez-Iturbe, I. On the Extraction of Channel Networks from Digital Elevation Data. Hydrol. Process. 1991, 5, 81-100. [CrossRef]

(C) 2019 by the authors. Licensee MDPI, Basel, Switzerland. This article is an open access article distributed under the terms and conditions of the Creative Commons Attribution (CC BY) license (http://creativecommons.org/licenses/by/4.0/). 